\title{
EFFECT OF HYPERBARIC OXYGEN EXPOSURE ON BACTERIAL TOXIN ANTIGEN AND COLLAGEN INDUCED ARTHRITIS IN ANIMAL MODEL
}

\author{
Harnanik T, ${ }^{1,2,3}$ Soeroso $J,{ }^{3}$ Suryokusumo MG, ${ }^{4}$ Juliandhy $T^{5}$
}

${ }^{1}$ Department of Hyperbaric, Drs. Med. R. Rijadi S., Phys. Naval Health Institute, ${ }^{2}$ Department of Physiology, Faculty of

Medicine, Hang Tuah University, ${ }^{3}$ Department of Biochemistry, Unit of the Experimental Animal, Faculty of Medicine,

Airlangga University, ${ }^{5}$ Department of Electrical Engineering, Hang Tuah University, Surabaya and ${ }^{4}$ Department of

Hyperbaric, Faculty of Medicine, Pembangunan National University, Jakarta, Indonesia

\begin{abstract}
Anti-cyclic citrullinated peptide antibody (ACPA) is a specific autoantibody that binds with citrulline amino acid in rheumatoid arthritis (RA). Interleukin-17a (IL-17a) is one of the cytokines that play an important role in chronic inflammation during the process of autoimmune diseases. Bacterial toxin antigen and collagen induced arthritis (ACIA) is the gold standard of RA animal model. The aim of this study was to see the effect of hyperbaric oxygen (HBO) exposure on ACIA animal models. ACIA model was made by combined antigens (bacterial toxin and collagen). A total of $24 \mathrm{male} \mathrm{Balb/C}$ mice modelled on ACIA were divided into three groups. Eight mice did not receive HBO exposure (control group, indicated as G1), eight mice (indicated as G2) received HBO exposure for 10 days while remaining eight mice (indicated as G3) for five days. G2 mice were exposed to HBO 2.4 ATA oxygen $100 \%$ for 90 minutes (30 minutes each with two intervals of five minutes breathing with normal air) for 10 consecutive days while G3 mice were exposed only for five days. The indicators of arthritis i.e. ACPA and IL-17a were measured by enzyme-linked immunosorbent assay (ELISA) technique. A significant decrease in ACPA and IL-17a levels was seen in both HBO exposed groups (G2 and G3) compared to G1 ( $\mathrm{p}<0.05)$. There was no significant difference in levels of ACPA and IL$17 \mathrm{a}$ in G3 mice and G2 mice ( $p>0.05)$. HBO reduced inflammation in ACIA by decreasing ACPA and IL-17a levels through improvement of hypoxic conditions and showed therapeutic potential for the treatment of RA.
\end{abstract}

\section{KEYWORDS}

Rheumatoid arthritis, inflammation, hyperbaric oxygen exposure, mice model.

\section{CORRESPONDING AUTHOR}

Dr. Titut Harnanik,

Department of Hyperbaric, Drs. Med. R. Rijadi S.,

Phys. Naval Health Institute, Indonesian Navy,

Surabaya, Indonesia.

Email: titut.harnanik1972@gmail.com; titut.

harnanik-2015@fk.unair.ac.id

ORCID ID: 0000-0003-1282-7614 


\section{INTRODUCTION}

Rheumatoid arthritis is a chronic autoimmune disease characterized by inflammation and joint damage. ${ }^{1}$ Hypoxia, a low oxygen partial pressure (pO2), plays an important role in the pathogenesis of RA and constitutes a specific feature of RA. Hypoxia induces angiogenesis, inflammation, apoptosis, cartilage erosion, abnormal energy metabolism and oxidative damage. Synovial hypoxia is considered to be a potential pathogenic factor in RA, lead to progressive immune infiltration of cells such as B cells, $\mathrm{T}$ cells and monocyte. $^{2}$

Auto-reactive B cell produces anti-cyclic citrullinated peptides antibody (ACPA), rheumatoid factor (RF) and anti-type II collagen (CII). ${ }^{3-5}$ ACPA is found to be about $95 \%$ of RA cases and has the highest specificity among the three autoantibodies. ${ }^{6,7}$ ACPA is primarily noticed as the persistent protein in the joint or circulation that contributes to the formation of the immune complex causes inflammation and joint destruction. Autoreactive T cells such as Th17 (T effector cells) are part of the proinflammatory Thcell producing IL-17a that contribute to RA. ${ }^{8,9}$ The balance between effector $\mathrm{T}$ cells and regulatory $\mathrm{T}$ cells determines whether autoreactive cells can induce an autoimmune response..$^{10}$ Drug and surgery are needed to control symptoms, manage pain and stop RA development. Hyperbaric oxygen (HBO) is a therapy by using $100 \%$ oxygen or higher levels oxygen than the normal air under the pressure and is done at more than 1-atmosphere absolute (ATA), usually 1.5 ATA to 3.0 ATA for 90 to 120 minutes using a highpressure air chamber. ${ }^{11}$ In this paper we present the effect of HBO exposure on the treatment of bacterial toxin antigen and collagen induced arthritis in animal model.

\section{MATERIALS AND METHODS}

\section{Research Design}

An experimental study (randomized control group the post-tests design) was carried out at Experimental Animal Unit of Department of Biochemistry, Faculty of Medicine, Airlangga University, and Drs. Med. R. Rijadi S., Phys., Naval Health Institute, Indonesian Navy, Surabaya, Indonesia. The sampling was done by simple random sampling technique.

\section{ACIA Model Mice}

In this study, we used 24 male Balb/c mice, aged 10-14 weeks, weight 20-30 grams and were induced with ACIA. Inflammatory arthritis marks (redness and swelling in both knee joints of mice) were observed by investigators following a standard protocol. The ACIA could induce chronic autoimmune arthritis in Balb/c mice that resulted in a rapid onset, exhibited intense inflammation and progressive joint damage in the knee joint. A total of 24 male Balb/C mice were used in this study and modelled on ACIA. The mice were then divided into three groups each groups consisted of eight mice: (1) control group, indicated as G1 (not exposed to HBO), (2) experimental group-2, indicated as G2 (exposed to HBO for 10 days) and (3) experimental group-3, indicated as G3 (exposed to HBO for five days).

Prior to ACIA induction, the mice were adapted at the Experimental Animal Unit of Department of Biochemistry, Faculty of Medicine, Airlangga University, Surabaya, Indonesia 14 days. Experiment was initiated after the full adaptation of mice. On day 0 , mice were immunized with $100 \mu \mathrm{g}$ methylated bovine serum albumin (mBSA) in $50 \mu \mathrm{l}$ phosphate buffer saline (PBS) emulsified with $50 \mu \mathrm{l}$ complete Freund's adjuvant (CFA) subcutaneously (s.c.). On day 7 , the mice were

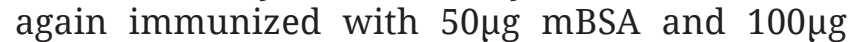
CII in $50 \mu \mathrm{l}$ PBS emulsified with $50 \mu \mathrm{l}$ incomplete Freund's adjuvant (IFA) (s.c.). On day 14, once again, the mice were immunized with $50 \mu \mathrm{g}$ mBSA and $100 \mu \mathrm{g}$ bovine type II collagen (CII) in $50 \mu \mathrm{l}$ PBS emulsified with 50 $\mu$ l IFA (s.c). In each immunization, 200ng of toxin Bordetella pertussis (PTx) was given intraperitoneally (i.p.). On the day 28 , arthritis was induced by injecting $50 \mu \mathrm{g}$ mBSA dissolved in $20 \mu \mathrm{l}$ PBS into the left knee (ipsilateral) cavity intra-articularly (i.a) while, the right knee joint (contralateral) cavity was injected with $20 \mu \mathrm{l}$ PBS in i.a.. Then, on the third week after induction of arthritis, ACIA model animals were obtained.

\section{HBO Exposure}

The $\mathbf{G} 2$ and $\mathbf{G} 3$ mice received oxygen exposure within the animal chamber at the Animal Research Laboratory of the Naval Health Institute, Indonesian Navy, Surabaya, Indonesia as shown in Fig. 1. The G2 mice received HBO exposure for 10 consecutive days while $\mathbf{G} 3$ mice received HBO exposure for 5 consecutive days followed by 5 days rest and again for 5 consecutive days HBO exposure. HBO exposure was given in the morning at the same hour at 7:00 western Indonesia time.

Each therapy session in animal model consisted of breathing normal air for 10 minutes from a pressure of 1 ATA to 2.4 ATA followed by breathing $\mathrm{O}_{2} 100 \%$ for 90 minutes (divided into three fraction each of 30 minutes with two intervals of five minutes breathing normal air) and then breathing normal air for 10 minutes at with lowered pressure (pressure of 1 ATA) in an animal chamber as shown in Fig. 2. 

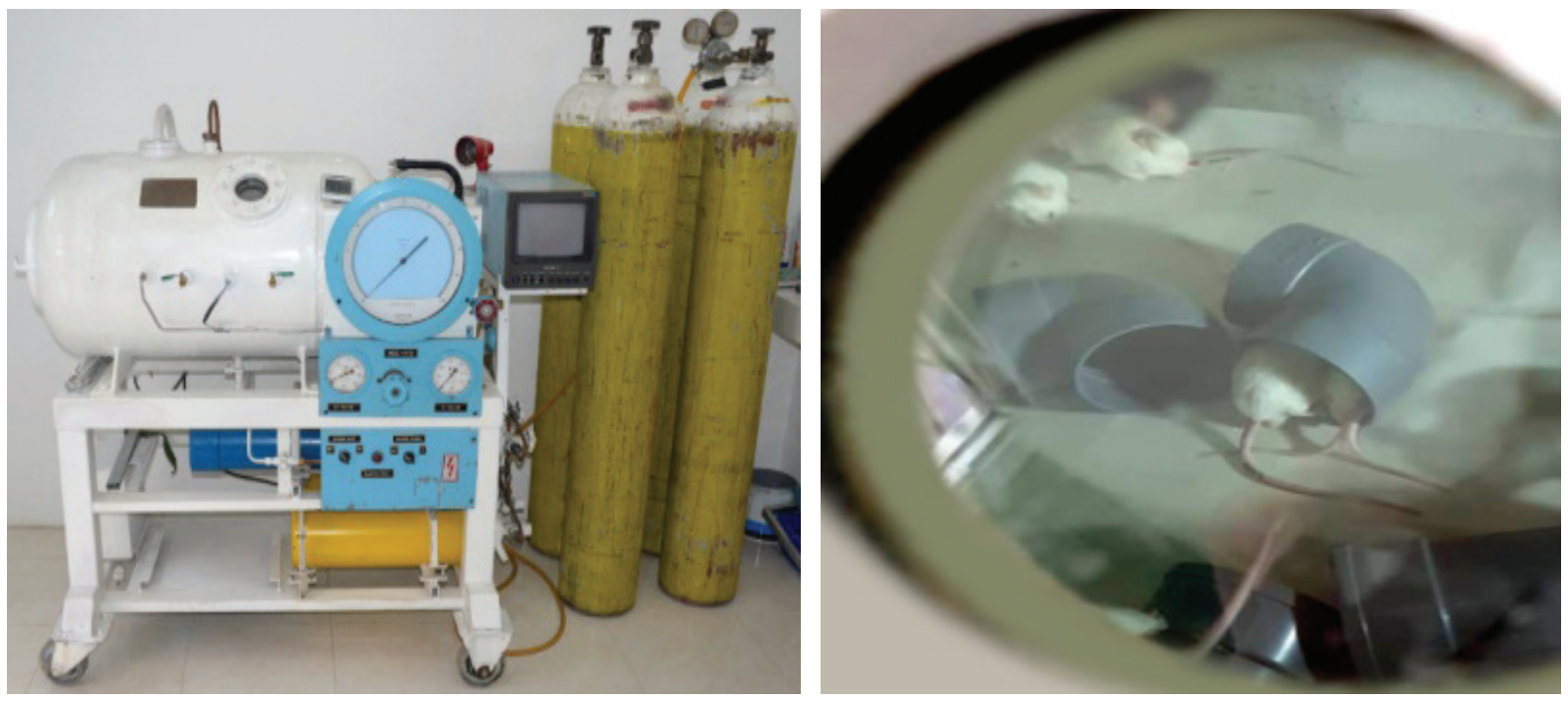

Fig. 1: Chamber designed and used of the exposure of HBO (left) and mice being exposed to $\mathrm{HBO}$ in the animal chamber (right)

\section{Sampling procedure}

Three hours after the completion ofHBO treatment, both G2 and G3 mice, were anaesthetized using ketamine 300mg / kgBW + xylazine 40mg / kgBW ip. It was confirmed that the mice have been completely anaesthetized by observing the "no signs of pain response". Then, blood sample was taken directly from the heart ventricle using $3 \mathrm{ml}$ disposable syringe needles. After that animals were euthanized.

In ACIA mice model, the examination of ACPA and IL-17a in the plasma was performed by ELISA following the procedures given by manufacturers. ACPA level was measured using mouse anticyclicalcitrullinated peptide antibody called Bioassay Technology Laboratory system (Korain Biotech Co., Ltd, Shanghai, China) with an ELISA reader (absorbance was measured at 450nm wavelengths) (Zenix-320 Microplate Reader). IL-17a levels were measured using mouse IL$17 \mathrm{a}$ antibody using same system used for the measurement of ACPA level.

\section{Data analysis}

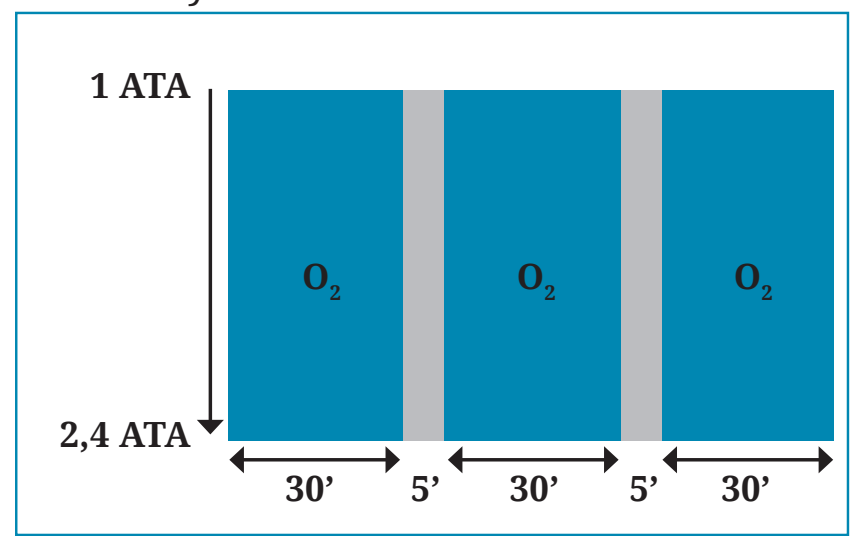

Fig. 2: HBO exposure duration in one session
The IBM SPSS statistics version 22.0 was used for all statistical analyses of data obtained. All data on the descriptive were expressed as mean value and standard deviation (SD). The level of significance for statistical analysis was considered as $\alpha=0.05$.

\section{Ethics Statement}

This study was performed in between January to April 2018 and the study was approved by the Ethics Committee of Drs. Med. R. Rijadi S., Phys., Naval Health Institute, Indonesian Navy, Surabaya, Indonesia. Standard protocols for animal handling, experimentation and disposal was followed.

\section{RESULTS AND DISCUSSION}

The level of ACPA and IL-17a level in three groups of mice are shown in Table 1 . The normality test using the Shapiro-Wilk test also showed significantly abnormal distribution of ACPA and IL-17a levels $(p<0.05)$. However, Lavene test results showed ACPA and IL-17a levels with homogeneous variance ( $p>0.05$ ) in both control group and the treatment groups.

The Kruskall Wallis test showed a significant difference in ACPA level ( $p=0.008 ; p<0.05$ ) among three experimental groups. The Mann Whitney test showed a significant decrease $(p=0.016$; $\mathrm{p}<0.05)$ in ACPA levels in the G2 compared to the G1 (control group) and there was a significant decrease $(p=0.005 ; p<0.05)$ in ACPA levels in the $\mathrm{G} 3$ compared to the G1. Although the average of ACPA levels was lower in the G3 treatment group compared to the G2 treatment group, there was no significant difference $(\mathrm{p}=0.529 ; \mathrm{p}>0.05)$ in ACPA levels after HBO exposure between in G2 
Table-1: Description of differences in ACPA and IL-17a levels between experimental groups.

\begin{tabular}{lcccc|} 
Group & \multicolumn{2}{c}{ ACPA $(\mathbf{n g} / \mathbf{m L})$} & \multicolumn{2}{c}{ IL-17a (ng/L) } \\
G1 & Mean & SD & Mean & SD \\
G2 & 1.436 & 0.77 & 41.076 & 10.27 \\
G3 & 0.643 & 0.37 & 19.213 & 7.13 \\
\hline
\end{tabular}

and G3 mice. Comparative test results of ACPA levels in the experimental groups are shown in Table 2 and Fig. 3.

The Kruskall Wallis test showed a significant difference in IL-17a levels $(p=0.006 \quad(p<0.05)$ among mine of three experimental groups (G1, G2 and G3). The Mann Whitney test showed a significant decrease in IL-17a levels in the G2 mice compared to the G1 mice (control) $p=0.002$ $(p<0.05)$, however, there was no significant decrease in IL-17a levels in the G3 mice compared to the G1 mice (control) $p=0.172(p>0.05)$. In the G2 and G3 (the treatment groups), the average of IL-17a levels was lower in the G2 mice compared to the G3 mice and there was a significant difference $p=0.046(p<0.05)$ in IL-17a levels after HBO exposure between in G2 and G3 treatment

\section{Table-2: Comparative test results of ACPA and} IL-17a levels in the experimental groups.

\begin{tabular}{llc} 
Group & ACPA (p) & IL-17a (p) \\
G1-G2-G3 & $\mathrm{p}=0.008$ & $\mathrm{p}=0.006$ \\
G1-G2 & $\mathrm{p}=0.016$ & $\mathrm{p}=0.002$ \\
G1-G3 & $\mathrm{p}=0.005$ & $\mathrm{p}=0.172$ \\
G2-G3 & $\mathrm{p}=0.529$ & $\mathrm{p}=0.046$ \\
\hline
\end{tabular}

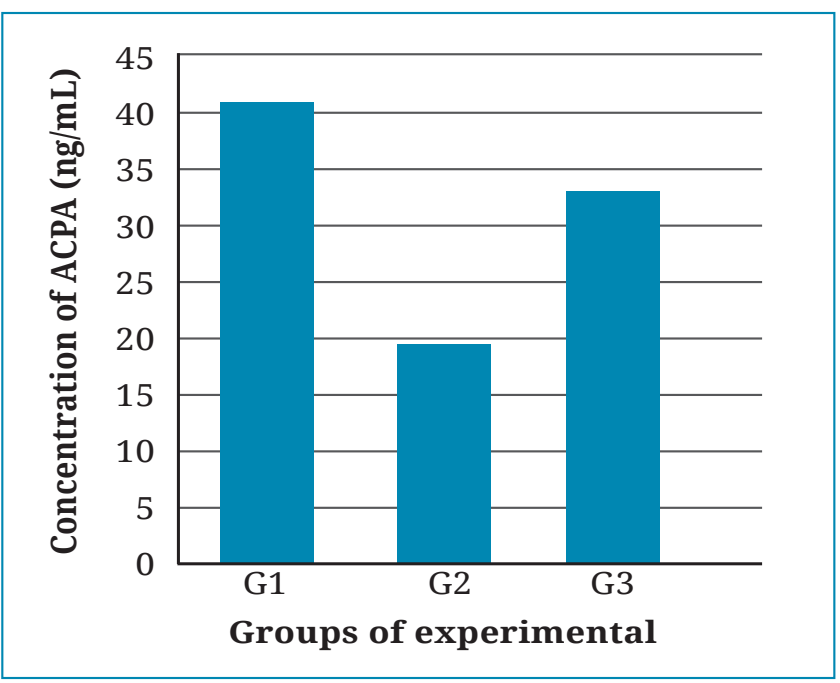

Fig. 3: The comparison diagram of the average of ACPA levels in the experimental groups groups. Comparative test results of IL-17a levels in the experimental groups are shown in Table 2 and Fig. 4.

In the ACIA injected experimental animals, there was a significant decrease in levels of ACPA and IL-17a in the treatment group (both G2 and G3) compared with G1 (control). This was attributed to the exposure to HBO that caused the partial pressure of oxygen to increase in the tissues resulting in tissue hypoxia repair in the treatment group. ${ }^{12}$

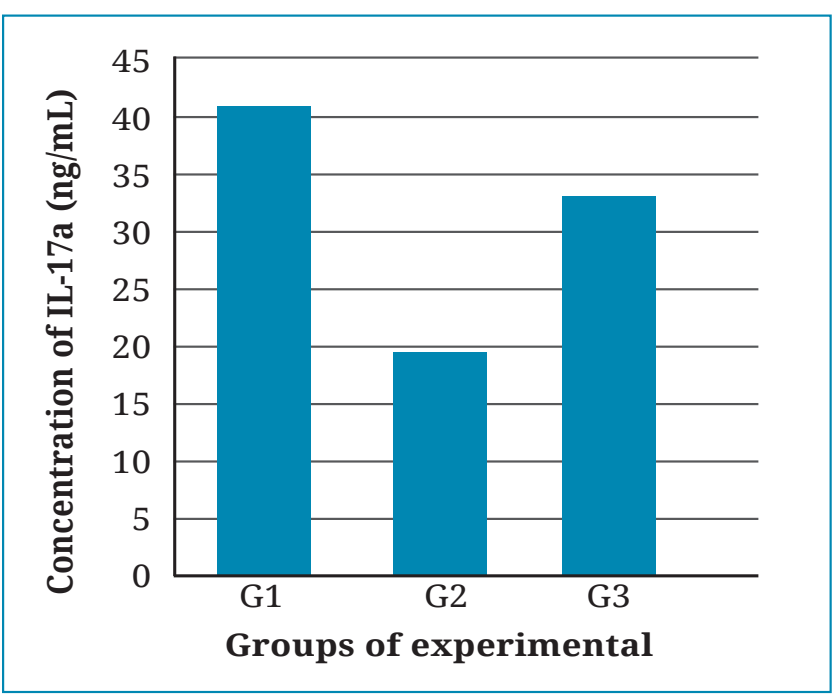

Fig. 4: The comparison diagram of the average IL-17a levels in the experimental groups.

In the normoxia condition, regulation occurred due to hypoxia-inducible factor (HIF) so that HIF levels decreased, because, HIF is the main sensor for changes in oxygen levels. ${ }^{13}$ The decrease of HIF inhibits Th17 development causing binding of transcriptional factor retinoic acid-related orphan nuclear receptor $\gamma(\mathrm{ROR} \gamma \mathrm{t}$ ) but directly activating the transcription factor for forkhead box P3 (FOXP3) resulting into an increase in $\mathrm{T}$ regulator formation. ${ }^{14} \mathrm{ROR} \gamma \mathrm{t}$ had a dominant role in cell differentiation and IL-17a production in all immune cells and other cell types including natural killer $\mathrm{T}$ cells, $\gamma \delta \mathrm{T}$ cells, lymphoid tissue inducer cells, neutrophils and macrophages. ${ }^{15}$ ROR $\gamma t$ synergized with other transcription factors such as transducer and activator of transcription 3 (STAT 3) signals to regulate transcription of the 
Th17 marker cytokine IL-17a, IL-17f, IL-21 and IL-22. ${ }^{16}$ The Th17 / Treg differentiation played an important role in homeostasis immune and pathogen clearance. ${ }^{17}$ Th17 differentiation into Treg caused decrease in IL-17a leading to activation of autoreactive $B$ cells that resulted into the production of ACPA autoantibodies decreasing in the HBO treatment group (G2 and G3). ${ }^{18}$

ACPA level in G3 mice was lower than in the G2 mice, however, the difference was not significant $(\mathrm{P}=>0.05)$. It could be explained that consecutive 10-day HBO therapy caused an increasing partial pressure of oxygen to increase the higher risk of reactive oxygen species (ROS) compared with a non-consecutive one. A 5-day break in the G3 mice led to an opportunity to regulate ROS levels so that ROS level was decreased. This condition could also cause $B$ autoreactive activity to decrease so that ACPA level in the G3 group was found to be lower than G2 group. ${ }^{19}$

Unlike ACPA, IL-17a level in G2 mice was lower than the G3 mice. The non-consecutive HBO exposure of a 5-day break in the G3 mice resulted in relative hypoxia inside the cell, especially the Th 17 lymphocytes, which is required for HIF activation. ${ }^{14}$ This condition could be explained by different of the system of regulation and transcription in cells within every cell of either B cell lymphocytes or $\mathrm{T}$ cells. ${ }^{18}$ Relative hypoxia is required to stabilize and increase HIF protein expression one of them HIF-1a in inducing differentiation of Treg cells into Th17 with involving E3 ubiquitin-protein ligase, an enzyme encoded by a gene that was a family of seven in absentia homologues (SIAH). ${ }^{20}$ The ubiquitin lease E3 SIAH1 and SIAH2 are thought to increase the activity of the IL-17a promoter in the T-cell line and to promote the development of Th17 ex vivo so that the production of IL-17a increased again although not significant. ${ }^{21}$

Conclusion: Exposure to HBO at different doses determines the effectiveness of therapy. Appropriate doses may provide the expected biomolecular effect. Present findings indicated that HBO can improve RA by decreasing levels of ACPA and IL-17a so that it can be an alternative therapy that is considered successful in reducing morbidity and mortality of RA patients.

\section{ACKNOWLEDGEMENTS}

This study received support from the Department of Physiology, Faculty of Medicine, Hang Tuah University, Surabaya, Indonesia; Department of Hyperbaric, Drs. Med. R. Rijadi S., Phys. Naval Health Institute, Indonesian Navy, Surabaya, Indonesia and Department of Biochemistry, Unit of the Experimental Animal, Faculty of Medicine, Airlangga University, Surabaya, Indonesia. This research was funded by Airlangga University and Hang Tuah University, Surabaya, Indonesia.

\section{REFERENCES}

1. Jeong H, Baek SY, Kim SW et al. Comorbidities of rheumatoid arthritis: Results from the Korean National Health and Nutrition Examination Survey. PLoS One 2017; 12: 1-15. doi:10.1371/journal. pone.0176260

2. Quiñonez-Flores CM, González-Chávez SA, PachecoTena C. Hypoxia and its implications in rheumatoid arthritis. J Biomed Sci 2016; 23: 1-9. doi:10.1186/ s12929-016-0281-0

3. Manivel VA, Mullazehi M, Padyukov L et al. Anticollagen type II antibodies are associated with an acute onset rheumatoid arthritis phenotype and prognosticate lower degree of inflammation during 5 years follow-up. Ann Rheum Dis 2017; 76: 1529-36. doi:10.1136/annrheumdis-2016-210873

4. Whittingham S, Stockman A, Rowley M. Collagen autoantibodies and their relationship to CCP antibodies and rheumatoid factor in the progression of early rheumatoid arthritis. Antibodies 2017; 6: 6 . doi:10.3390/antib6020006

5. Pelzek AJ, Grönwall C, Rosenthal P et al. Persistence of Disease-Associated Anti-Citrullinated Protein Antibody-Expressing Memory B Cells in Rheumatoid Arthritis in Clinical Remission. Arthritis Rheumatol 2017; 69: 1176-86. doi:10.1002/art.40053
6. Salehi-Abari I. Autoimmune diseases and therapeutic approaches open access 2016 ACR/ EULAR Revised Criteria for too early diagnosis of rheumatoid arthritis (Letter to Editor). Autoimmune Dis Therapeutic Approaches 2016; 33. doi:10.14437/2378-6337-3-120

7. Alivernini S, Galeazzi M, Peleg $\mathrm{H}$ et al. Is ACPA positivity the main driver for rheumatoid arthritis treatment? Pros and cons. Autoimmun Rev 2017; 16: 1096-102. doi:10.1016/j.autrev.2017.09.002

8. Kuwabara T, Ishikawa F, Kondo M, Kakiuchi T. The role of IL-17 and related cytokines in inflammatory autoimmune diseases. Mediators Inflamm 2017; doi:10.1155/2017/3908061

9. Hashimoto M. Th17 in animal models of rheumatoid arthritis. J Clin Med 2017; 6: 73. doi:10.3390/ jcm6070073

10. Al-Zifzaf DS, El Bakry SA, Mamdouh $\mathrm{R}$ et al. FoxP3+T regulatory cells in rheumatoid arthritis and the imbalance of the Treg/TH17 cytokine axis. Egypt Rheumatol 2015; 37: 7-15. doi: 10.1016/j. ejr.2014.06.004

11. Xu Y, Ji R, Wei R, Yin B, He F, Luo B. The efficacy of hyperbaric oxygen therapy on middle cerebral 
artery occlusion in animal studies: A meta-analysis. PLoS One 2016; 11: 1-14. doi:10.1371/journal. pone.0148324

12. Fife CE, Eckert KA, Carter MJ. An update on the appropriate role for hyperbaric oxygen: Indications and evidence. Plast Reconstr Surg 2016; 138: 107S-16S. doi:10.1097/PRS.0000000000002714

13. Chen R, Lai UH, Zhu L, Singh A, Ahmed M, Forsyth NR. Reactive Oxygen Species Formation in the Brain at Different Oxygen Levels: The Role of Hypoxia Inducible Factors. Front Cell Dev Biol 2018; 6: 132. doi:10.3389/fcell.2018.00132

14. Chou T, Chuang $\mathrm{Y}$, Hsieh $\mathrm{W}$ et al. Tumour suppressor death-associated protein kinase targets cytoplasmic HIF-1a for Th17 suppression. Nature Communications 2016; 7: 11904. doi: 10.1038/ ncomms11904

15. Talia DM, Deliyanti D, Agrotis A, WilkinsonBerka JL. Inhibition of the nuclear receptor ROR $\gamma$ and interleukin-17A suppresses neovascular retinopathy. Arterioscler Thromb Vasc Biol 2016; 36: 1186-96. doi:10.1161/ATVBAHA.115.307080

16. Wang R, Solt LA. Metabolism of murine TH17 cells: Impact on cell fate and function. Eur J Immunol
2016; 46: 807-16. doi:10.1002/eji.201545788

17. Lubberts E. The IL-23-IL-17 axis in inflammatory arthritis. Nat Rev Rheumatol 2015; 11: 415-29. doi:10.1038/nrrheum.2015.53

18. Calabresi E, Petrelli F, Bonifacio AF, Puxeddu I, Alunno A. Patogenesis de AR. Clin Exp Rheumatol 2018: 175-84. doi:29716677

19. Kienhöfer D, Boeltz S, Hoffmann MH. Reactive oxygen homeostasis - The balance for preventing autoimmunity. Lupus 2016; 25: 943-54. doi:10.1177/0961203316640919

20. Joseph Barbi1, Drew M. Pardoll1, and Fan Pan. Ubiquitin-dependent regulation of Foxp3 and Treg function. Immunol Rev 2015; 266: 27-45. doi:10.1111/imr.12312.

21. Lee JH, Elly C, Park Y, Liu YC. E3 Ubiquitin Ligase VHL regulates hypoxia-inducible factor-1a to maintain regulatory $\mathrm{T}$ cell stability and suppressive capacity. Immunity 2015; 42: 1062-74. doi:10.1016/j. immuni.2015.05.016 